\title{
Self-Regulation of Slow Cortical Potentials in Psychiatric Patients: Alcohol Dependency ${ }^{1}$
}

\author{
Frank Schneider, 2,3,4 Thomas Elbert, ${ }^{5}$ Hans Heimann, ${ }^{3}$ \\ Andreas Welker, ${ }^{3}$ Friedhelm Stetter, ${ }^{3}$ Regina Mattes, ${ }^{3}$ \\ Niels Birbaumer, ${ }^{6,7}$ and Karl Mann $^{3}$
}

Ten unmedicated alcohol-dependent male inpatients participated in a Slow Cortical Potential (SCP) self-regulation task utilizing biofeedback and instrumental conditioning. These patients were hospitalized for treatment of alcohol dependency after chronic abuse of alcoholic beverages. Somatic withdrawal symptomatology had occurred recently and the patients were free of any withdrawal symptoms of the autonomic nervous system. Immediately after hospitalization patients were unable to control their SCPs without the reinforcement of immediate feedback across 4 sessions. Seven patients participated in a fifth session an average of 4 months later. Six out of these 7 patients had not had a relapse at the follow-up. In the fifth session these patients were immediately able to differentiate between the required negativity and negativity suppression, whereas the seventh patient, who had relapsed, was unable to control his brain potentials successfully. Results are further evidence that some of the frontocortical dysfunctions in alcohol-dependent patients are reversible. This could covary with a morphological restitution of the cortex.

Descriptor Key Words: slow cortical potentials; alcohol dependency; biofeedback; instrumental learning; CNV.

\footnotetext{
${ }^{1}$ The authors are grateful to Waldemar Himer, Brigitte Rockstroh, and Werner Lutzenberger for their theoretical and technical support. We would also like to thank Ilse M. Zalaman for her assistance in the preparation of this manuscript. Research was supported by the Bundesminister für Forschung und Technologie, Germany, and the Deutsche Forschungsgemeinschaft (SFB 307).

${ }^{2}$ Address all correspondence to Dr. Frank Schneider, Department of Psychiatry, University of Pennsylvania, 10th Floor, Gates Building, Philadelphia, PA 19104.

${ }^{3}$ Department of Psychiatry, University of Tübingen, Germany.

${ }^{4}$ Department of Psychiatry, University of Pennsylvania, U.S.A.

5 Institute for Experimental Audiology, University of Münster, Germany.

${ }^{6}$ Department of Clinical and Physiological Psychology, University of Tübingen, Germany

${ }^{7}$ Dipartimento di Psicologia Generale, Università Degli Studi, Padova, Italia.
} 
As reported in Parts I and II of this publication series (Schneider, Rockstroh, Heimann, Lutzenberger, Mattes, Elbert, Birbaumer, \& Bartels, 1992; Schneider, Heimann, Mattes, Lutzenberger, \& Birbaumer, 1992) we consider slow-varying shifts of surface recorded EEG (SCPs) to represent neuronal excitability in the underlying cortical networks. The area specific regulation of excitability is thought to indicate the direction of preparatory attention (Elbert, in press; McCallum, 1988; Rockstroh, Elbert, Canavan, Lutzenberger, \& Birbaumer, 1989). Therefore the investigation of the selfregulation of SCPs may serve to establish some mechanisms required for attentive behavior. The findings reported in Part I demonstrated such impaired self-regulatory mechanisms in patients with schizophrenia (Schneider, Rockstroh et al., 1992). In this study subjects were required to modify their SCPs upon command. In a biofeedback design, position and movement of a visual feedback stimulus represented the change in SCPs during the 8 -s feedback interval. Schizophrenic patients, unlike control subjects, showed no significant differentiation between volitional negativity increase and negativity suppression in the first few sessions, but achieved SCP-control after extensive training (sessions 18-20). In contrast to the schizophrenic patients, depressives quickly learned to regulate their SCPs and to maintain this ability across 20 sessions (Schneider, Heimann et al., 1992).

Several studies have demonstrated similar endogenous event-related potentials as the reduced CNV for schizophrenics, alcoholics, and alcoholintoxicated healthy controls (Kopell, Tinklenberg, \& Hollister, 1972; Rohrbaugh et al., 1988; Skerchock \& Cohen, 1984; Timsit-Berthier, Gerono, Rousseau, Mantanus, Abraham, Verhey, Lamers, \& Edmonds, 1984). The reduced CNV may suggest reduced attentional preparation, which in connection with perseveration tendencies observed in alcoholics may point to a frontocortical deficit, as has been shown by neuropsychological and morphological studies (Berglund et al., 1987; Corbett \& Harper, 1988; Fitzhugh, Fitzhugh, \& Reitan, 1965; Götze, Kühne, Hansen, \& Knipp, 1978; Harper, Kril, \& Karpy, 1987; Harper, Kril, \& Daly, 1988; Jones \& Parsons, 1971; Oscar-Berman \& Ellis, 1987; Sachs, Russel, Christman, \& Cook, 1987; Samson, Baron, Feline, Baries, \& Crouzel, 1986; Tarter, 1975). Investigations of alcohol-dependent patients thus may contribute to our understanding of frontal lobe functioning.

Follow-up studies of alcohol-dependent patients with a longer period of abstinence are especially important, since several studies have shown morphological, neurophysiological, and neuropsychological restitution of the cortex even after extensive periods of abuse (Artmann, Gall, Hacker, \& Herrlich, 1981; Cala et al., 1983; Carlen, Wortzman, Holgate, Wilkinson, \& Rankins, 1978; Grünberger \& Maly, 1972; Mann, Optiz, Petersen, 
Schroth, \& Heimann, 1989; Muuronen, Bergman, Hindmarsh, \& Telakivi, 1989; Porjesz \& Begleiter, 1985; Ron, Acker, Shaw, \& Lishman, 1982; Schroth, Naegele, Klose, Mann, \& Petersen, 1988; Templer, Ruff, \& Simpson, 1975).

The aim of the present study was to show that chronic alcohol-dependent patients, like other patients with frontal lobe disorders (Birbaumer, Elbert, Canavan, \& Rockstroh, 1990), demonstrate a reduced ability in $\mathrm{SCP}$-self-regulation, and that SCP-control recovers with increasing periods of alcohol abstinence.

\section{METHOD}

The same experimental procedures employed in Parts I and II of this publication series) were also used in the present investigation. Therefore apparatus and design will only be described briefly (for a more detailed description see Schneider, Rockstroh et al., 1992).

\section{Subjects}

Ten chronic alcohol-dependent male inpatients recruited from a $6-$ week detoxification program participated in this study. Only those subjects were accepted who met the diagnosis "alcohol dependency" according to DSM-III-R. Patients suffering from head trauma, migraine headache, stroke, other psychiatric illnesses (such as depression) or any other disease requiring medical treatment were excluded from the sample. Somatic withdrawal symptomatology had occurred recently and the patients were free of any withdrawal symptoms of the autonomic nervous system at study onset. Patients were all right-handed (Edinburgh Inventory, Oldfield, 1971). Table I provides the patient description.

\section{Apparatus and Physiological Recordings}

All aspects of experimental control and data acquisition were accomplished on-line by digital computers. Physiological signals were amplified with a 30 -s time constant (high-frequency cutoff $30 \mathrm{~Hz}$ ), digitized at 100 $\mathrm{Hz}$, and digitally filtered to 10 points per second. EEG-recordings were taken from $C_{z}$ referenced to linked earlobe electrodes separated from the common input by a resistor to prevent shunt currents between them. Vertical EOG recordings were measured between electrodes $1 \mathrm{~cm}$ above and $1 \mathrm{~cm}$ below the right eye. 
Table I. Description and SCP Differentiation in the Second Transfer Block of the Patients with Alcohol Dependency

\begin{tabular}{|c|c|c|c|c|c|c|c|}
\hline \multirow[b]{2}{*}{ Patient } & \multirow[b]{2}{*}{ Age } & \multirow{2}{*}{$\begin{array}{l}\text { Duration } \\
\text { of alcohol } \\
\text { dependency } \\
\text { (in years) }^{a}\end{array}$} & \multicolumn{2}{|c|}{$\begin{array}{l}\text { Alcohol consumption } \\
\text { within the last } 3 \\
\text { months (g/day) }\end{array}$} & \multirow{2}{*}{$\begin{array}{l}\text { Duration } \\
\text { of } \\
\text { abstinence } \\
\text { before } \\
\text { study onset } \\
\text { (in days) }\end{array}$} & \multirow{2}{*}{$\begin{array}{l}\text { Gamma- } \\
\text { glutamyl- } \\
\text { transferase } \\
\text { (I.U./1) at } \\
\text { study onset }\end{array}$} & \multirow{2}{*}{$\begin{array}{c}\mu \mathrm{V} \\
\text { (average } \\
\text { across } \\
\text { session } \\
1 \text { to } 4 \text { ) }\end{array}$} \\
\hline & & & Mean & Maximum & & & \\
\hline 1 & 28 & 9 & 165 & 420 & 4 & 34 & 0.03 \\
\hline 2 & 30 & 3 & 200 & 420 & 0 & 13 & -2.67 \\
\hline 3 & 37 & 5 & 100 & 180 & 0 & 92 & -2.01 \\
\hline 4 & 34 & 6 & 185 & 330 & 0 & 155 & -0.27 \\
\hline 5 & 44 & 1 & 200 & 220 & 30 & 75 & 0.57 \\
\hline 6 & 29 & 14 & 100 & 400 & 2 & 33 & -2.10 \\
\hline 7 & 39 & 5 & 180 & 220 & 12 & 75 & 2.87 \\
\hline 8 & 31 & 1 & 160 & 200 & 0 & 106 & -5.16 \\
\hline 9 & 24 & 4 & 120 & 230 & 17 & 10 & 3.19 \\
\hline 10 & 52 & 14 & 200 & 260 & 0 & 48 & -3.39 \\
\hline Mean & 35.2 & 6.2 & 161 & 287 & 6.5 & 64.1 & -0.89 \\
\hline
\end{tabular}

${ }^{a}$ Defined as the first loss of control and/or symptoms of somatic dependency.

\section{Design and Procedure}

Continuous visual SCP feedback was provided in each 8-s trial on a TV screen. The feedback stimulus was a rocket ship which moved in a horizontal plane through a gap. The subjects' task in each trial was to move the rocket ship from left to right out of the gap and to produce a supranormal SCP-shift on the "negativity" trial or a suppression of negativity on the "positivity" trial depending on the presented discriminative stimulus (either the letter A or B). At the end of each session the subjects received money on the bases of their success rate (between $\$ 2$ and $\$ 8$ (U.S.) per session).

The position of the rocket represented a linear function of the integrated EEG measured as change from the mean of a 1-s pretrial baseline. Whenever vertical eye movements of the same polarity as the required slow potentials were detected, a time-out contingency was used to prevent rocket movement (Elbert, Rockstroh, Lutzenberger, \& Birbaumer, 1980).

"Transfer" trials were included in each session in order to assess response control without feedback (the rocket). These trials contained the letters A or B but no rocket. Each session consisted of 110 trials and was comprised of alternate blocks of 30 feedback trials and 20 transfer trials. Alcohol-dependent patients participated in 4 sessions on 4 consecutive days immediately following hospital admittance. 


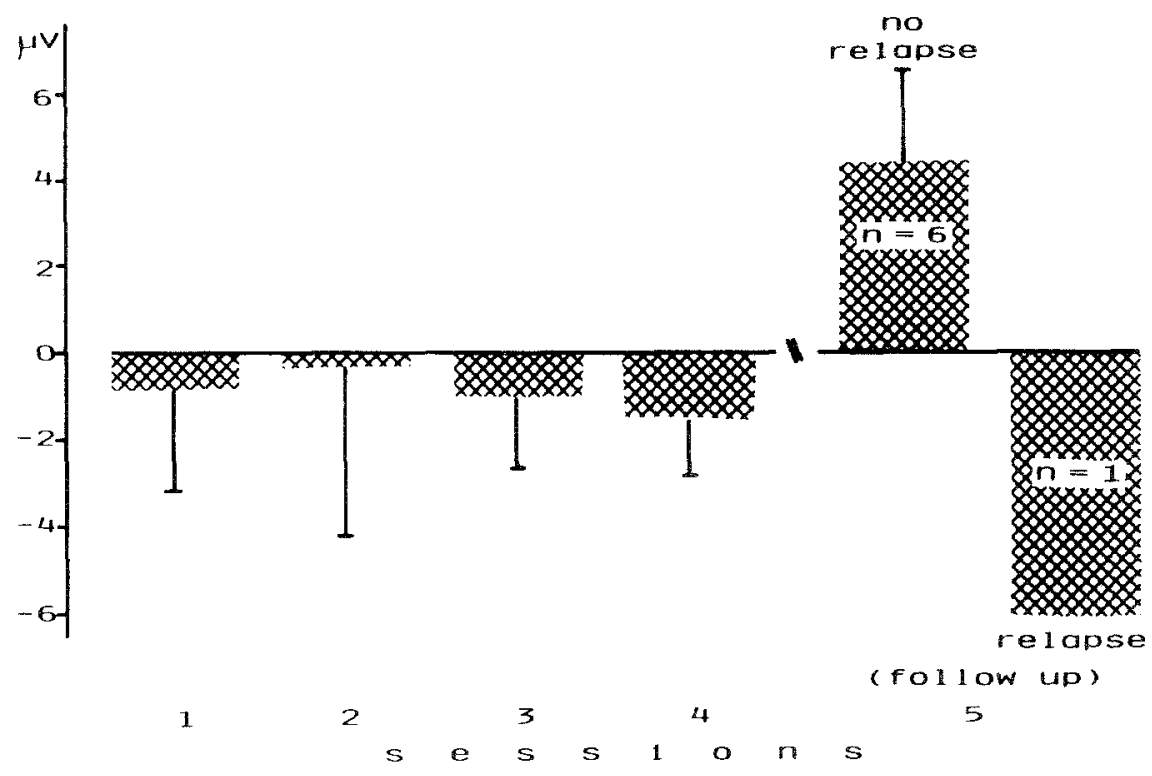

Fig. 1. Mean differentiation of SCPs in $\mu \mathrm{V}$ in the second transfer block between negativity and positivity trials in 10 patients with alcohol dependency over 5 sessions and 7 patients during the follow-up (bars mark $\mu \mathrm{V}$ averages).

Seven alcohol-dependent patients (Patient 1, 2, 3, 4, 5, 7, 10) agreed to participate in a fifth session some weeks after the detoxification treatment. During that time they participated in weekly group sessions in an outpatient treatment program. Abstinence was monitored with laboratory tests. Six of them stayed sober; one relapsed. Of the three remaining alcohol-dependent patients 2 were unable to attend because of their job and one canceled without explanation. The elapsed time between the 4th and 5 th session was between 6 and 25 weeks which amounted to an average of 16.7 weeks $(S D=7.3)$.

\section{Data Reduction and Analysis}

Trials were excluded in which the DC-shift in the EEG-channel or EOG-channel exceeded $100 \mu \mathrm{V}$ or $70 \mu \mathrm{V}$, respectively. Changes in vertical eye movements were assessed in the same manner as SCPs: There were no significant differences across the different conditions. SCPs were calculated by subtracting the mean SCP recorded during the last second of the 
Table II. Mean Differentiation (+SE) Between Negativity and Negativity Suppression Trials in Microvolts

\begin{tabular}{lccc}
\hline & Sessions & \multicolumn{2}{c}{ Session 5 follow-up } \\
\cline { 2 - 4 } & $1-4^{a}$ & No relapse $^{b}$ & Relapse $^{c}$ \\
\hline Transfer 1 & 1.39 & 3.27 & 6.93 \\
& \pm 1.62 & \pm 2.33 & \\
Feedback 1 & 0.70 & 2.28 & -7.14 \\
& \pm 0.85 & \pm 2.78 & -14.05 \\
Feedback 2 & 3.90 & 2.38 & \\
& \pm 1.26 & \pm 2.24 & -5.60 \\
Transfer 2 & -0.89 & 4.38 & \\
& \pm 0.85 & \pm 2.20 & \\
\hline
\end{tabular}

$a_{n}=10$.

$b_{n}=6$.

${ }^{c_{n}}=1$.

pretrial period from the mean SCP recorded during the 8-s feedback period.

Data from the last feedback-and-transfer trials of every session were submitted to ANOVAs and post-hoc tests.

\section{RESULTS}

SCP differentiations for the second transfer block across the 4 sessions for alcohol-dependent patients were not significant $(-0.89 \mu \mathrm{V} ; t(9)$ $=-1.06)$, in comparison to the results from the second feedback block $(3.90 \mu \mathrm{V} ; t(9)=3.10 ; \mathrm{p}=.006)$ (Figure 1 , Tables I and II).

At the follow-up (average of 4 months later) 6 alcohol-dependent patients (those without relapse) attained a significant SCP-differentiation of $4.38 \mu \mathrm{V}(t(5)=1.99 ; p=.05)$ during the second transfer block, but no significant differentiation during the second feedback block $(2.38 \mu \mathrm{V} ; t(5)$ $=1.06$ ). Patient 1 (who suffered a relapse within the follow-up period) was not able to successfully control his SCPs in the feedback or transfer trials.

\section{DISCUSSION}

At the beginning of the detoxification program alcohol-dependent patients were able to regulate their SCPs only in the presence of immediate feedback. Like schizophrenic patients at the beginning of their biofeedback training (Schneider, Rockstroh et al., 1992), alcohol-dependent patients were also unable to modify their SCPs in the transfer conditions; i.e., they were unable to generalize SCP control without the presence of immediate feedback. 
Similar failures of SCP modification in SCP self-regulation tasks have been observed in subjects at risk for a psychotic development (Elbert, Lutzenberger, Rockstroh, \& Birbaumer, 1983), in patients with bilateral frontal lesions (Lutzenberger et al., 1980), epileptic patients (Birbaumer, Elbert, Rockstroh, Daum, \& Wolf, in press), and in individuals with attentional dysfunctions (Rockstroh, Elbert, Lutzenberger, \& Birbaumer, 1990). Such similarities may indicate a common factor of impaired SCP regulation or, in patients, point to an impaired ability to adequately generalize SCP control. Signs of dysfunctional frontal lobe activity have frequently been observed in these patient groups. Since prefrontal regions are directly involved in the regulation of selective attention and the timing of behavior, particularly in delayed response tasks (Fuster, 1989), we assume that the regulatory deficit observed in patients with alcohol dependency and schizophrenia may reflect - at least in part - frontal lobe irregularities. This assumption is supported by findings that demonstrated that patients learned to perform responses upon command when immediate feedback and reward was provided, but completely failed to do so during transfer conditions, when reinforcement was delayed, i.e., was provided at the end of the session (monetary reward). This response pattern literally mimics the one that we observed earlier in patients with bilateral frontal lobe lesions (Lutzenberger et al., 1980).

In the literature frontocortical impairment in alcohol-dependent patients has been associated with attentional and behavioral disorders. Tarter (1975) reviewed the findings on alcohol-dependent patients and found that they match to a great extent findings of patients with frontal brain lesion. Skerchock and Cohen (1984) suggested that a reduced CNV in chronic alcohol-dependent patients indicates a specific frontal lobe dysfunction.

In the follow-up session (5th session) the effects of a longer abstinence period on SCP regulation were assessed. Six patients, who stayed sober for approximately 4 months, and 1 relapsed patient, participated in this session. SCP differentiation was significant in transfer for the patients without relapse and nonconsiderable for the relapsed patient. The results support the fact that the greatest SCP differentiation increase occurs during transfer. SCP differentiation in feedback was not significant, which may indicate that the information processing of the feedback stimulus may have prevented negativity development (Rockstroh et al., 1989). Thus, after a longer period of alcohol abstinence, patients learned SCP control as normals. This is supported by the present evidence, which shows that those patients abstinent more than 3 days before study onset already demonstrated positive differentiation during transfer in the first few sessions while all others achieved negative variations (see Table I). 
In this study alcohol-dependent patients learned to modify their SCPs after abstaining from alcohol for a longer period of time. The hypothesis that the frontal lobe impairment in chronic alcohol-dependent patients is indeed reversible (Harper et al., 1988) is supported by our present findings. Our results are thus in agreement with reports that demonstrate evidence for reversibility of frontal lobe impairment, such as improvement in cognitive performance in alcohol abstinency after neuronal regeneration (McMullen, Saint-Cyr, \& Carlen, 1984) and reversible brain damage (Carlen et al., 1978) even after extended periods of abuse.

\section{REFERENCES}

Artmann, H., Gall, M. V., Hacker, H., \& Herrlich, J. (1981). Reversible enlargement of cerebral spinal fluid spaces in chronic alcoholics. American Journal of Neuroradiology, 2, 23-27.

Berglund, M., Hagstadius, S., Risberg, J., Johanson, T. M., Bliding, A., \& Mubrin, Z. (1987). Normalization of regional cerebral blood flow in alcoholics during the first 7 weeks of abstinence. Acta Psychiatrica Scandinavica, 75, 202-208.

Birbaumer, N., Elbert, T., Canavan, A. G. M., \& Rockstroh, B. (1990). Slow potentials of the cerebral cortex and behavior. Physiological Review, 70, 1-41.

Birbaumer, N., Elbert, T., Rockstroh, B., Daum, I., \& Wolf, P. (in press). Clinical-psychological treatment of epilepsy. In T. Elbert, I. Florin, \& J. Fliegenbaum, (Eds.), Perspectives and promises in clinical psychology. New York: Plenum.

Cala, L. A., Jones, B., Burns, P., Davis, R. E., Stenhouse, N., \& Mastaglia, M. L. (1983). Results of computerized tomography, psychometric testing and dietary studies in social drinkers, with emphasis on reversibility after abstinence. Medical Journal of Australia, 2, 264-269.

Carlen, P. L., Wortzman, G., Holgate, R. C., Wilkinson, D. A., \& Rankin, J. G. (1978). Reversible cerebral atrophy in recently abstinent chronic alcoholics measured by computer tomography scans. Science, 200, 1076-1078.

Corbett, D., \& Harper, C. (1988). A golgi study of the cortical neurones in alcoholics. Neuroscience Letters, 30 (Suppl.), 59.

Elbert, T. (in press). Slow cortical excitability. In W. C. McCallum (Ed.), Slow potential changes in the human brain. New York: Plenum.

Elbert, T., Rockstroh, B., Lutzenberger, W., \& Birbaumer, N. (1980). Biofeedback of slow cortical potentials. I. Electroencephalography and Clinical Neurophysiology, 48, 293-301.

Elbert, T., Lutzenberger, W., Rockstroh, B., \& Birbaumer, N. (1983). When regulation of slow brain potentials fails - A contribution to the psychophysiology of perceptual aberration and anhedonia. In C. Perris, D. Kemali, \& M. Koukkou-Lehman, (Eds.), Clinical neurophysiological aspects of psychopathological conditions (pp. 99-106). Basel: Karger.

Fitzhugh, L. C., Fitzhugh, K. B., \& Reitan, R. M. (1965). Adaptive abilities and intellectual functioning of hospitalized alcoholics: Further considerations. Quarterly Journal Studies of Alcohol, 26, 402-411.

Fuster, J. M. (1989). The prefrontal cortex: Anatomy, physiology and neuropsychology of the frontal lobe (2nd ed.). New York: Raven.

Götze, P., Kühne, D., Hansen, J., \& Knipp, H. P. (1978). Hirnatrophische Veränderungen bei chronischem Alkoholismus. Archiv für Psychiatrie und Nervenkrankheiten, 226, 137-156.

Grünberger, J,, \& Maly, J. (1972). Experimenteller Beitrag zur Erfassung der Aufmerksamkeitszuwendung bei Alkoholkranken. Wiener Zeitschrift für Nervenheilkunde, $30,39-45$. 
Harper, C. G., Kril, J. J., \& Daly, J. M. (1987). Are we drinking our neurons away? British Medical Journal (Clinical Research), 294, 534-536.

Harper, C. G., Kril, J. J., \& Daly, J. M. (1988). Brain shrinkage in alcoholies is not caused by changes in hydration: A pathological study. Joumal of Neurology, Neurosurgery and Psychiatn, 51, 124-127.

Jones, B., \& Parsons, O. A. (1971). Impaired abstracting ability in chronic alcoholics. Archives of General Psychiatry, 24, 71-75.

Kopell, B. S., Tinklenberg, J. R., \& Hollister, L. E. (1972). Contingent negative variation amplitudes. Marihuana and alcohol. Archives of General Psychiatry, 27, 809-811.

Lutzenberger, W., Birbaumer, N., Elbert, T., Rockstroh, B., Bippus, W., \& Breidt, R. (1980). Self-regulation of slow cortical potentials in normal subjects and patients with frontal lobe lesions. In H. H. Kornhuber \& L. Deecke (Eds.), Motivation, motor and sensory processes of the brain. Electrical potentials, behavior and clinical use (pp. 427-430). Amsterdam: Elsevier.

Mann, K., Opitz, H., Petersen, D., Schroth, G., \& Heimann, H. (1989). Intracranial CSF volumetry in alcoholics: Studies with MRI and CT. Psychiatry Research, 29, 277-279.

McCallum, W. C. (1988). Potentials related to expectancy, preparation and motor activity. In T. W. Picton (Ed.), Human event-related potentials - Handbook of electroencephalography and clinical neurophysiology, Vol. 3 (pp. 427-453). Amsterdam: Elsevier.

McMullen, P. A., Saint-Cyr, J. A., \& Carlen, P. L. (1984). Morphological alterations in rat CA1 hippocampal pyramidal cell dendrites resulting from chronic ethanol consumption and withdrawal. Journal of Comparative Neurology, 225, 111-118.

Muuronen, A., Bergman, H., Hindmarsh, T., \& Telakivi, T. (1989). Influence of improved drinking habits on brain atrophy and cognitive performance in alcoholic patients: A 5-year follow-up study. Alcoholism: Clinical and Experimental Research, 13, 137-141.

Oldfield, R. C. (1971). The assessment and analysis of handedness: The Edinburgh Inventory. Neuropsychologia, 9, 97-113.

Oscar-Berman, M., \& Ellis, R. J. (1987). Cognitive deficits related to memory impairments in alcoholism. In M. Galanter (Ed.), Recent developments in alcoholism, Vol. 5 (pp. 59-80). New York: Plenum.

Porjesz, B., \& Begleiter, H. (1985). Human brain electrophysiology and alcoholism. In R. F. Tarter \& D. H. van Thiel (Eds.), Alcohol and the brain (pp. 139-182). New York: Plenum.

Rockstroh, B., Elbert, T., Canavan, A., Lutzenberger, W., \& Birbaumer, N. (1989). Slow cortical potentials and behaviour (2nd ed.). Baltimore: Urban \& Schwarzenberg.

Rockstroh, B., Elbert, T., Lutzenberger, W., \& Birbaumer, N. (1990). Biofeedback: Evaluation and therapy in children with attentional dysfunctions. In A. Rothenberger (Ed.), Brain and behavior in child psychiatry (pp. 345-357). Berlin: Springer.

Rohrbaugh, J. W., Stapleton, J. M., Frowein, H. W., Adinoff, B., Varner, J. L., Lane, E. A., Eckardt, M. J., \& Linnoila, M. (1988). Acute effects of ethanol on motor performance and movement-related brain potentials. Advances in Alcohol and Substance Abuse, 7, 53-57.

Ron, M. A., Acker, W., Shaw, G. K., \& Lishman, W. A. (1982). Computerized tomography of the brain in chronic alcoholism. A survey and follow-up study. Brain, 105, 497-514.

Sachs, H., Russel, J. A. G., Christman, D. R., \& Cook, B. (1987). Alteration of regional cerebral glucose metabolic rate in non-Korsakoff chronic alcoholism. Archiv für Neurologie, 44, 1242-1251.

Samson, Y., Baron, J, C., Feline, A., Bories, J., \& Crouzel, C. (1986). Local cerebral glucose utilisation in chronic alcoholics: A positron tomography study. Journal of Neurology, Neurosurgery and Psychiatry, 49, 1165-1170.

Schneider, F., Rockstroh, B., Heimann, H., Lutzenberger, W., Mattes, R., Elbert, T., Birbaumer, N., \& Bartels, M. (1992). Self-regulation of slow cortical potentials in psychiatric patients: Schizophrenia. Biofeedback and Self-Regulation, 17, 277-292.

Schneider, F., Heimann, H., Mattes, R., Lutzenberger, W., \& Birbaumer, N. (1992). Self-regulation of slow cortical potentials in psychiatric patients: Depression. Biofeedback and Self-Regulation, 17, 203-214. 
Schroth, G., Naegele, T., Klose, U., Mann, K., \& Petersen, D. (1988). Reversible brain shrinkage in abstinent alcoholics, measured by MRI. Neuroradiology, 30, 121-126.

Skerchock, J. A., \& Cohen, J. (1984). Alcoholism, organicity and event-related potentials. Annals of the New York Academy of Science, 425, 623-628.

Tarter, R. E. (1975). Psychological deficit in chronic alcoholics: A review. International Journal of Addictions, 10, 327-368.

Templer, D. I., Ruff, C. F., \& Simpson, K. (1975). Trail making test performance of alcoholics abstinent at least a year. International Journal of Addictions, 10, 609-612.

Timsit-Berthier, M., Gerono, A., Rousseau, J., Mantanus, H., Abraham, P., Verhey, F. H. M., Lamers, T., \& Edmonds, P. (1984). An international pilot study of CNV in mental illness - Second report. In R. Karrer, J. Cohen, \& P. Tueting (Eds.), Brain and information. Annals of the New York Academy of Science, 425, 629-637. 